\title{
High Directivity Microstrip Coupler Using Variable Width Structure
}

\author{
S.Maheswari ${ }^{1}$, T.Jayanthy ${ }^{2}$ \\ ${ }^{1}$ (Research Scholar, Sathyabama University, India) \\ ${ }_{2}^{2}$ (Principal, Panimalar Institute of Technology, India)
}

\begin{abstract}
A method to improve the directivity of the microstrip coupler is presented. The width of the coupler is modified for phase velocity compensation which results in high directivity. Using this procedure, a $15 \mathrm{~dB}$ coupler is designed and simulated at $0.9 \mathrm{GHz}$ using SONNET software. A high directivity of $46 \mathrm{~dB}$ is obtained. The validity of the design concept is verified and compared with conventional coupler by simulations.
\end{abstract}

Keywords: coupled lines, directional coupler, microstrip, and microwave.

\section{Introduction}

Microstrip couplers are widely used in microwave applications such as antenna feeds, balanced mixers, modulators, phase shifters and so on. But, they suffer from poor directivity, due to the inequality between the odd and even mode phase velocities. Various compensation techniques have been reported to improve the directivity. The wiggly line coupler [1] improves the directivity and suffers due to lack of design equation. The capacitive compensation was used to improve the directivity [2]; however the capacitor has to be placed in the narrow spacing between the coupled lines. The inductive compensation improves the isolation and needs the iteration design process [3,4]. The coupled spur line [5], and reflected power canceller approach [6] work within a narrow band. The Epsilon negative transmission line [7] was used but it needs more number of unit cells to improve the accuracy, which leads to fabrication difficulty. Delay lines [8] were used, but the coupler occupies more space than the conventional one. The Re-entrant mode structure [9], periodic metallic cylinders [10], and metamaterial [11] were also reported to improve the isolation, where the coupler construction is complex. Periodic floating conductors [12] were used to improve the directivity for a wide bandwidth for a maximum directivity of $30 \mathrm{~dB}$.

In this paper, the directivity of the coupler is improved, using the phase velocity compensation method. It is obtained by modifying the width of the coupler. The phase velocity of the even and odd modes can be varied by varying the distributed inductance and capacitance of microstrip lines of the coupler. These distributed parameters can be varied by modifying the width of the microstrip coupler structure. In the proposed coupler, inductance and capacitance of the microstrip lines are varied by varying the width of the microstrip lines. In one microstrip line, the width of the microstrip line is reduced by introducing slots at one end of the microstrip line and increased at the other end. In another microstrip line, the width of the microstrip line is kept constant. Even though the structure becomes asymmetric, the characteristic impedance of each microstrip line is maintained to be $50 \mathrm{ohms}$ by properly selecting the width of the microstrip line.

Using this method a $15 \mathrm{~dB}$ microstrip coupler is designed, and isolation of the coupler is improved up to $64.4 \mathrm{~dB}$. Advantages of the proposed method are that the structure is planar, there is no special fabrication technique needed, construction is simpler and it does not require any iteration design process.

\section{Design Of Microstrip Coupler}

The dimension ratios of the microstrip coupler are calculated using the design procedure given in [13]. we assume that port impedance Zo, coupling $(\mathrm{dB})$ and, the operational frequency are known parameters at beginning of the design. The even and odd impedances, $Z_{\mathrm{oe}}$ and $\mathrm{Z}_{\mathrm{oo}}$, of the microstrip coupler can be found as

$$
\begin{aligned}
& Z_{o e}=Z_{o} \sqrt{\frac{1+c}{1-c}} \\
& Z_{o o}=Z_{o} \sqrt{\frac{1-c}{1+c}}
\end{aligned}
$$




$$
\frac{w}{h}=8 \frac{\sqrt{\left(\exp \left[\frac{R}{42.4} \sqrt{\varepsilon_{r}+1}\right]-1\right)\left(\frac{\left.7+\frac{4}{\varepsilon_{r}}\right)+\frac{1+\frac{1}{\varepsilon_{r}}}{11}}{0.81}\right.}}{\left(\exp \left[\frac{R}{42.4} \sqrt{\varepsilon_{r}+1}\right]-1\right)}
$$

$(\mathrm{w} / \mathrm{h})_{\text {se }}$ and $(\mathrm{w} / \mathrm{h})_{\text {so }}$ are the shape ratios for the equivalent single case corresponding to even mode and odd mode geometry respectively and are found as

$$
\begin{aligned}
& (w / h)_{s e}=\left.(w / h)\right|_{R=\frac{Z_{o e}}{2}} \\
& (w / h)_{s o}=\left.(w / h)\right|_{R=\frac{Z_{o o}}{2}}
\end{aligned}
$$

The corrected term $(\mathrm{w} / \mathrm{h})^{\prime}$ so is given as

$$
\left(\frac{w}{h}\right)_{s o}^{\prime}=0.78\left(\frac{w}{h}\right)_{s o}+0.1\left(\frac{w}{h}\right)_{s e}
$$

Then the spacing ratio $\mathrm{s} / \mathrm{h}$ can be found as

$$
\frac{s}{h}=\frac{2}{\pi} \cosh ^{-1}\left[\frac{\left.\cosh \left[\frac{\pi}{2}\left(\frac{w}{h}\right)_{s e}\right]+\cosh \left[\frac{\pi}{2}\left(\frac{w}{h}\right)_{s o}^{\prime}\right]-2\right]}{\cosh \left[\frac{\pi}{2}\left(\frac{w}{h}\right)_{s o}^{\prime}\right]-\cosh \left[\frac{\pi}{2}\left(\frac{w}{h}\right)_{s e}\right]}\right]
$$

and the physical length of the coupler is calculated using

$$
l=\frac{\lambda}{4}=\frac{c}{4 f \sqrt{\varepsilon_{e f f}}}
$$

where $\varepsilon_{\text {eff }}$ can be calculated using (9) as given in [14]

$$
\varepsilon_{\text {eff }}=\frac{\varepsilon_{r}+1}{2}+\frac{\varepsilon_{r}-1}{2}\{F(w / h)\}-\frac{\varepsilon_{r}-1}{4.6} \frac{t / h}{\sqrt{w / h}}
$$

$F(w / h)=\left(1+\frac{12}{w / h}\right)^{-0.5}+0.04[1-(w / h)]^{2}$ for $\mathrm{w} / \mathrm{h} \leq 1$

$F(w / h)=\left(1+\frac{12}{w / h}\right)^{-0.5}$ for $\mathrm{w} / \mathrm{h} \geq 1$

where, $\mathrm{c}=3^{*} 10^{8} \mathrm{~m} / \mathrm{sec}$ and $\mathrm{f}$ is operational frequency in $\mathrm{Hz}$ and $\varepsilon_{\text {eff }}$ is the effective permittivity constant of the coupled structure and $t$ is the thickness of the conductor.

\section{Simulated Results}

Using the above design procedure a conventional $15 \mathrm{~dB}$ microstrip coupler is designed using FR4 substrate $\left(\mathcal{E}_{\mathrm{r}}=4.4, \mathrm{~h}=1.6 \mathrm{~mm}\right)$ with design values are width of the microstrip line $(\mathrm{w}=0.3 \mathrm{~cm})$, spacing between the lines $(\mathrm{s}=0.07 \mathrm{~cm})$ and the length of the coupler $(l=4.6 \mathrm{~cm})$ at $0.9 \mathrm{GHz}$. The microstrip coupler structure is simulated using the SONNET software and is shown in Fig 1. In the Fig 1, port 1, 2 indicates the input and through port. Port 3, 4 indicates the coupled port and isolated port. The simulated results are shown in Fig 2. 


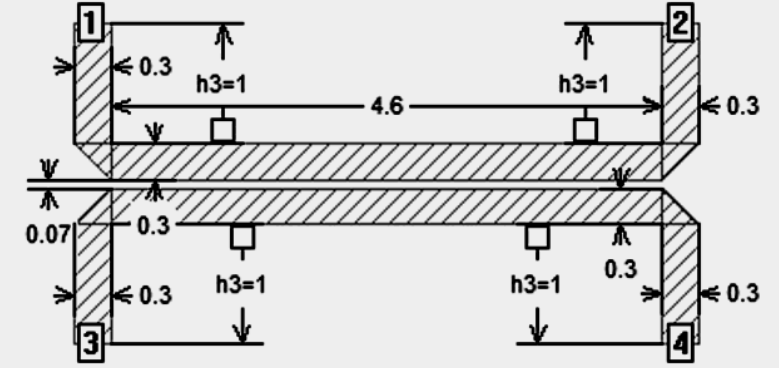

Fig. 1. Structure of simulated conventional microstrip coupler (All dimensions are in $\mathrm{cm}$ )

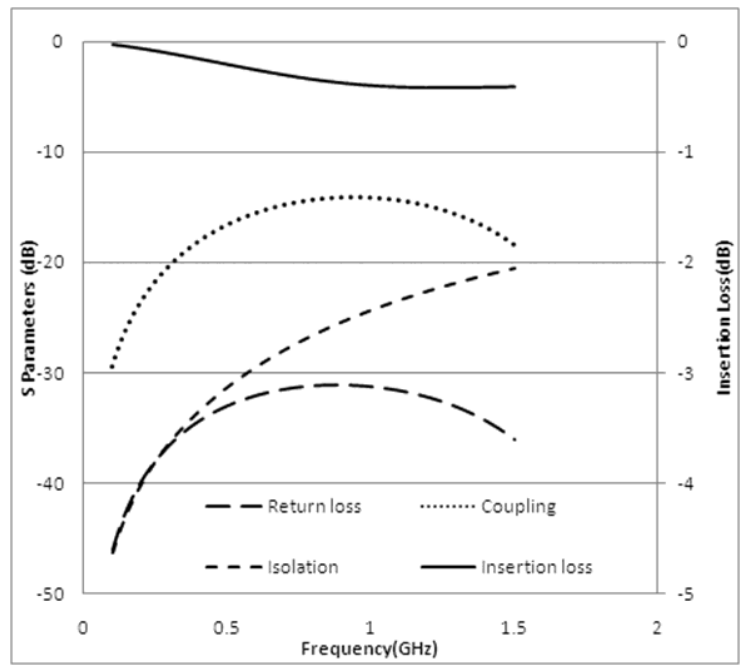

Fig. 2. Simulated result of a conventional microstrip coupler

The simulation results show that coupling value obtained is $14.1 \mathrm{~dB}$ with return loss of $31.1 \mathrm{~dB}$ and insertion loss of $0.37 \mathrm{~dB}$. The microstrip coupler has an isolation of $25.3 \mathrm{~dB}$ at $0.9 \mathrm{GHz}$. Thus the conventional coupler has a directivity of $11 \mathrm{~dB}$ only. The directivity of the coupler can be improved using phase velocity compensation method. In one microstrip line, the width of the microstrip line is reduced by introducing slots at one end of the microstrip line and increased at the other end. In another microstrip line, the width of the microstrip line is kept constant. Using this method a microstrip coupler is designed with design values are same as that of conventional microstrip coupler in addition to that, in microstrip line 2 the dimensions of depth and width of the slot is $\mathrm{h} 1=0.28 \mathrm{~cm}$ and $\mathrm{w} 1=0.4 \mathrm{~cm}$ and additional increase in width is $\mathrm{q}=0.9 \mathrm{~cm}$ for a length of $\mathrm{p}=0.7 \mathrm{~cm}$. There are three slots are used in the design with same slot dimensions. The period between the slots is $1 \mathrm{~cm}$. All the dimensions are shown in $\mathrm{cm}$ in Fig 1. The simulation is done using SONNET software. The parameters w1, h1, p $\& \mathrm{q}$ are optimized for higher directivity in simulation. The simulated structure of the proposed coupler is shown in Fig 3. The simulated results of the proposed coupler are shown in Fig 4.

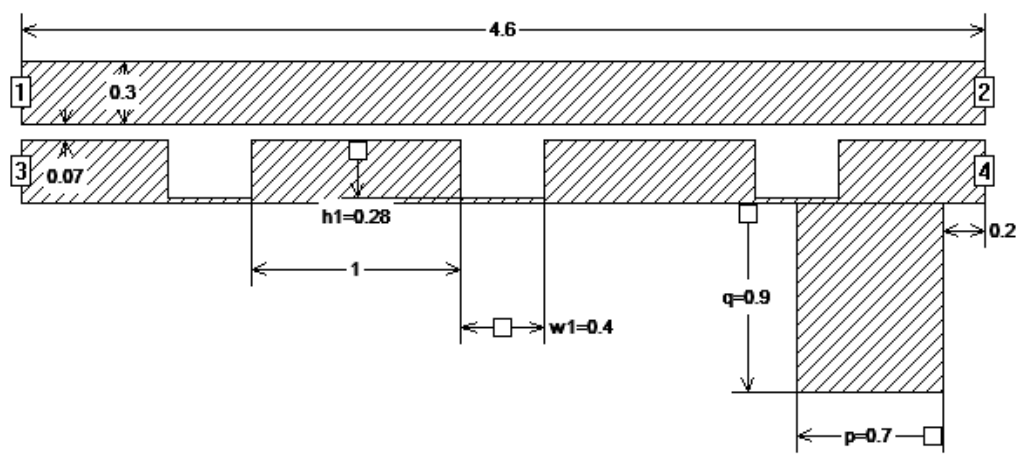

Fig. 3. Structure of proposed microstrip coupler 


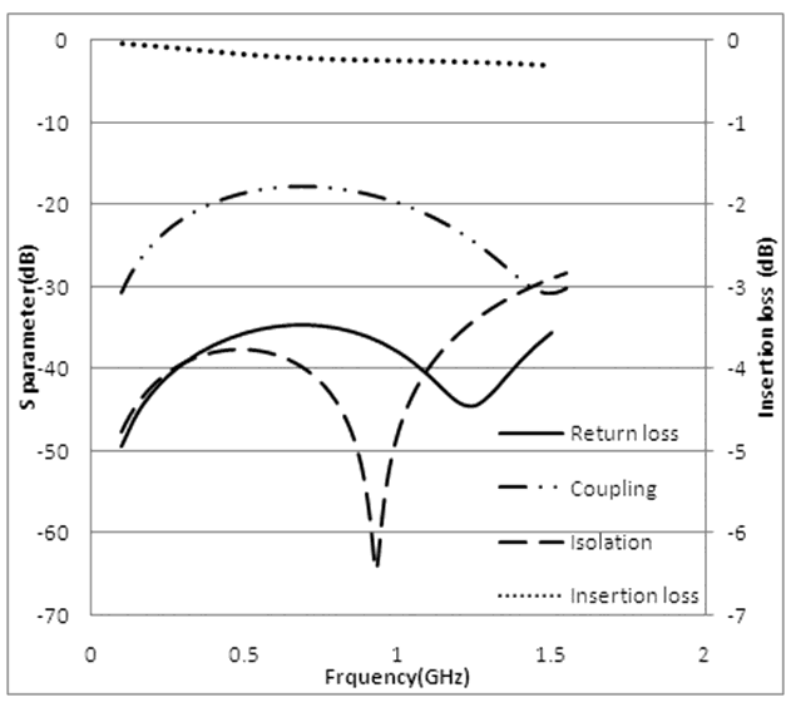

Fig 4. Simulated results of proposed coupler

For the proposed coupler, a maximum isolation of $64.4 \mathrm{~dB}$ is obtained for $0.93 \mathrm{GHz}$ in simulation. The simulated coupling is $18.6 \mathrm{~dB}$ at $0.9 \mathrm{GHz}$. A maximum directivity of $46 \mathrm{~dB}$ is obtained at $0.93 \mathrm{GHz}$. For a conventional coupler the isolation is $25 \mathrm{~dB}$ only. Thus the proposed coupler improves the isolation up to $64.4 \mathrm{~dB}$. The simulated value of insertion loss and return loss are $0.24 \mathrm{~dB} \& 36.1 \mathrm{~dB}$ which are better than the conventional coupler. The comparison between the simulated results of the proposed coupler and conventional coupler are shown in Figs $5 \& 6$. The limitation of the coupler is its narrow bandwidth. The dimensions of the slot should be selected properly for the required coupling otherwise the coupling will be reduced.

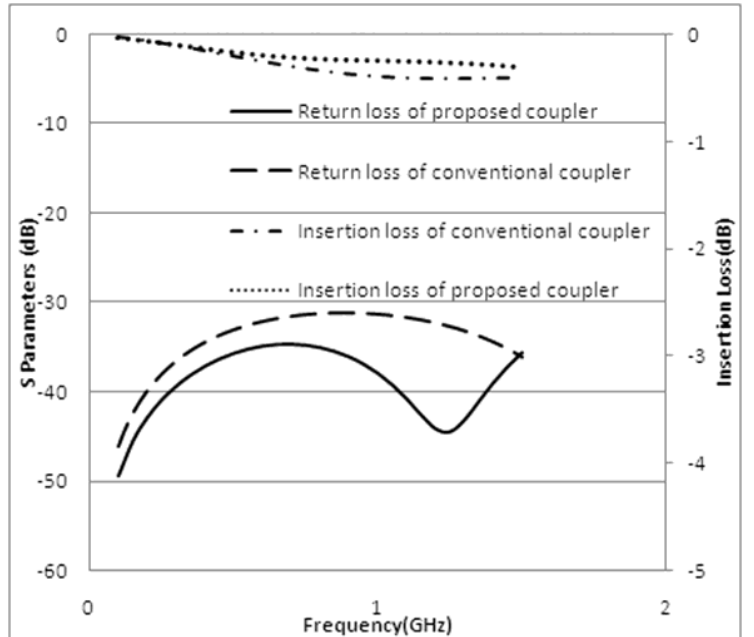

Fig 5. Comparison of $\mathrm{S}_{11} \& \mathrm{~S}_{21}$ of conventional and proposed coupler

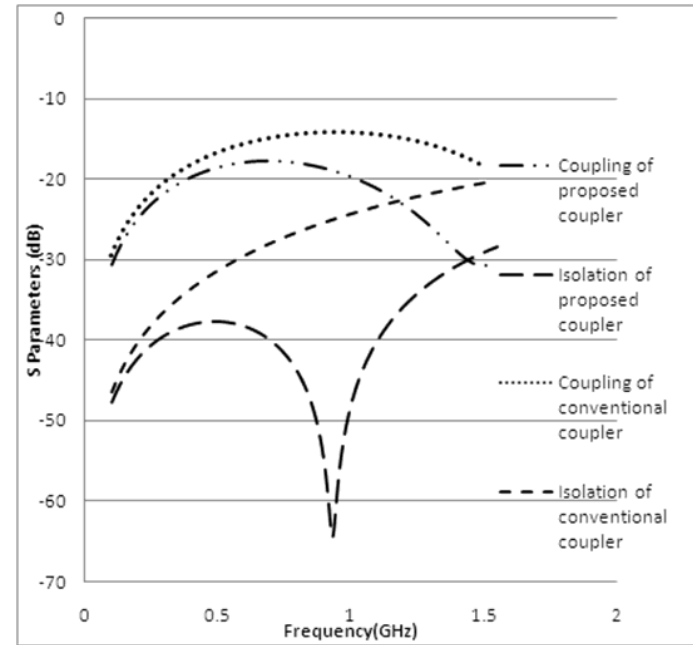

Fig 6. Comparison of $\mathrm{S}_{31} \& \mathrm{~S}_{41}$ of conventional and proposed coupler

\section{Conclusion}

A microstrip coupler with high directivity has been presented. The coupler width is modified to change the pattern of the structure for phase velocity compensation. Using this procedure, $15 \mathrm{~dB}$ microstrip coupler is designed and simulated at $0.9 \mathrm{GHz}$ using SONNET software. A high directivity of $46 \mathrm{~dB}$ is obtained. The coupler structure is planar and construction is simpler. It can be used for RFID applications.

\section{References}

[1]. A. Podell, “A high directivity microstrip coupler technique," in IEEE MTT-S Int. Microw. Symp. Dig., pp.33-36, May, 1970.

[2]. M. Dydyk, "Microstrip directional couplers with ideal performance via single-element compensation," IEEE Trans. Microw. Theory Tech., vol.47, no. 6, pp. 956-964, Jun. 1999.

[3]. R. Phromloungsri, M. Chongcheawchamnan, and I. D. Robertson, "Inductively compensated parallel coupled microstrip lines and their applications," IEEE Trans. Microw. Theory \&Tech., vol.54, no.9, pp.3571-3582, Sep.2006.

[4]. S. Lee and Y. Lee, "An inductor-loaded microstrip directional coupler for directivity enhancement," IEEE Microw. Wireless Compon. Lett., vol. 19, no. 6, pp. 362-364, Jun. 2009. 
[5]. S.-F. Chang, J.-L. Chen, Y.-H. Jeng and C.-T. Wu, "New high-directivity coupler design with coupled spurlines," IEEE Microw. Wireless Compon. Lett., vol. 14, no. 2, pp. 65-67, Feb. 2004.

[6]. D.-Z. Chen, X.-W. Shi, Y.-Y. Yang, and F. Wei, "Compact microstrip parallel coupler with high isolation,” Electron. Lett, vol. 44, no. 12, pp. 740-741, Jun. 2008.

[7]. A. Pourzadi, A. Attari and M. Majedi, "A Directivity-Enhanced directional coupler using Epsilon Negative Transmission line," IEEE Trans. Microw. Theory Tech., vol. 60, no. 11, pp. 3395-3402, Nov. 2012

[8]. Y.-H. Chun, J.-Y. Moon, S.-W. Yun, and J.-K. Rhee, “Microstrip line directional couplers with high directivity,” Electron. Lett, vol. 40, no. 5, pp. 317-318, Mar. 2004.

[9]. C.-S. Kim, S.-W. Lee, P.-Y. Lee, H.-S. Kim, J.-S. Park \& Dal Ahn, "Design of Re- entrant mode microstrip directional coupler for high directivity performance," in Asia-Pacific Microw. Conf. Dig., 2000, pp. 1286-1289.

[10]. J. Shi, X.Y. Zhang, K.W. Lau, J.-X. Chen and Q. Xue, "Directional couplers with high directivity using metallic cylinders on microstrip line," Electron. Lett., vol. 45, no.8, pp. 415-417, Apr. 2009.

[11]. Chun, Y.-H., and Hong, J.-S.: 'High directivity directional coupler using metamaterial'. Eur. Microwave Conf., Manchester, UK, 2006, pp. 329-331.

[12]. Takao Fujii, Yoshihiro Kokubo, and Isao Ohta, "High Directivity Quarter-Wave Microstrip Couplers with Periodic FloatingConductors on Coupled Edges". Proceedings of the 36th European Microwave Conference, pp.32-35, Sept. 2006.

[13]. Abdullah Eroglu \& Jay Kynoon Lee, "The Complete Design of microstrip directional couplers using synthesis technique," IEEE Trans. Instrum. Meas., Vol.57, no.12, pp.2756-2761, Dec.2008

[14]. I. Bahl and P. Bhartia, Microwave Solid State Circuit Design.Wiley, New York, 1988, p.18. 